\title{
Measurement of the Elastic Constants of Carbon Fiber Board Based on Modal Analysis
}

\begin{abstract}
Zhaoyu Shen, ${ }^{\mathrm{a}}$ Yuhang He, ${ }^{\mathrm{a}}$ Usama Sayed, ${ }^{\mathrm{b}}$ Jun Wang, ${ }^{\mathrm{a}}$ Yuhao Zhou, ${ }^{\mathrm{a}}$ and Zheng Wang ${ }^{\mathrm{a}, *}$
As a strategic new material with excellent performance, carbon fiber has attracted much attention in the wood structure industry. In this paper, the test modal and computational modal analysis methods are used to study the mode shape and modal parameters of carbon fiber board, calculate the elastic constants, i.e., the elastic modulus, shear modulus, and Poisson's ratio, and analyze the coupling of the results. The conclusions show that the numerical results of the mode shape and elastic constants of the carbon fiber board obtained via the computational modal and test modal analysis are highly coupled. The first-order bending and first-order torsional modes of the carbon fiber board obtained via the two analysis methods are consistent, and the frequency error rate is less than $5 \%$. The error rates of the elastic modulus and shear modulus are $0.7 \%$ and $7.8 \%$, respectively. In addition, the research is conducive to strengthening the work of finite element computational modal analysis, and better promoting the application of non-destructive testing and quality grading of carbon fiber board. The above-mentioned optimization design work for improving the dynamic characteristics of carbon fiber board, and further research on the detection and optimization of the performance when the carbon fiber material is combined with wood, also has engineering application value for promoting the faster development of the wood structure market.
\end{abstract}

DOI: 10.15376/biores.17.1.255-268

Keywords: Carbon fiber board; Modulus of elasticity; Shear modulus; Poisson's ratio; Computational modal analysis; Test modal analysis

Contact information: a: College of Materials Science and Engineering, Nanjing Forestry University, Nanjing 210037 China; b: Joint International Research Laboratory for Bio-composite Building Materials and Structures, Nanjing Forestry University 210037 China;

* Corresponding author: wangzheng63258@163.com

\section{INTRODUCTION}

The ancient buildings in China primarily adopted a wood frame structure, which is both light and beautiful as well as providing strong seismic resistance. However, due to the limitations of wood in terms of degradation resistance, fire prevention, as well as its old age, most of the existing ancient buildings are seriously damaged and need to be repaired (Yang et al. 2021). With the development of science and technology, more new materials and technologies have been applied to the protection of ancient buildings, which brings convenience to the protection of ancient buildings (Corbi et al. 2021; Liang et al. 2021; Xuan et al. 2021; Zhang et al. 2021). Since metal components are prone to corrosion when they are used to reinforce wood structures, the total additional weight will increase, which is not conducive to the reinforcement of wood structures (Dauletbek et al. 2021). Moreover, the traditional reinforcement method will cause damage to the building itself 
(Ashraf et al. 2021; Liang et al. 2021; Xuan et al. 2021; Zhang et al. 2021). In recent years, with the continuous improvement of carbon fiber technology, carbon fiber materials have been used for the reinforcement of wood structures. Carbon fiber reinforcement technology has obvious advantages, primarily including its remarkable reinforcement effect, excellent degradation resistance and durability, no impact on the appearance of the structure, basically no change in the dead weight of the original structure, good fatigue resistance, etc. (Li et al. 2007; Gezer and Aydemir 2010). Therefore, wood structures are strengthened with carbon fiber, which includes carbon fiber cloth and carbon fiber board. Carbon fiber is a new material developed to meet the needs of aerospace, aviation, and other military departments. Its density is less than $1 / 4$ of the density of steel, and its strength is 5 to 7 times greater than steel (Chen and Wang 2010). Compared with aluminum alloy structural parts, the weight reduction effect of carbon fiber can reach $20 \%$ to $40 \%$, compared with steel parts. The weight reduction effect of carbon fiber can reach up to $60 \%$ to $80 \%$. The specific strength of carbon fiber is 5 times higher than the specific strength of steel and 4 times higher than the specific strength of aluminum alloy (Yang et al. 2011). The specific modulus is 1.3 to 12.3 times greater than other structural materials. In addition, when the carbon fiber component is overloaded, it will cause a small amount of fiber fracture, and then the load will be transmitted and dispersed to other intact fibers so that the component will not lose its bearing capacity in a short time. These characteristics are enough to validate its excellent damage safety properties, and carbon fiber is easy to form in a large area (Wang et al. 2012). The manufacturing method of integral curing can be used, which greatly reduces the number of parts and fasteners, simplifies the production process, and shortens the production cycle. At present, carbon fiber is widely used in bridge reinforcement, aerospace applications, the military industry, medical technology, and other fields.

Since the 1980s, American researchers have developed carbon fiber cloth with superior properties, e.g., light weight, high strength, a high modulus, corrosion resistant, and high fatigue resistant, which has been widely used in reinforcement projects. In 1997, China began to engage in research on carbon fiber reinforcement and its usage for the repair of civil building structures and completed the first engineering application of carbon fiber reinforced concrete structures in 1998. In 2014, ASTM standard C1557 (2014) proposed a standard test method for fiber tensile strength and elastic modulus. In terms of research on the elastic constants of carbon fiber, Duan et al. (2020) and Guruprasad et al. (2020) conducted nano-indentation tests on carbon fiber through the study of the indentation modulus. Using the numerical relationship between the indentation modulus and the elastic constant, the elastic modulus, in-plane shear modulus, and Poisson's ratio were determined through reverse analysis. Mesquita et al. (2021) used the fiber mechanical properties obtained via automated single fiber tensile test equipment to convert the load displacement diagram into a stress-strain diagram after performing compliance calibration, from which the elastic modulus and strength were extracted. Kim et al. (2009) calculated the in-plane shear modulus of composites using a simple relationship composed of the tensile modulus and Poisson's ratio. However, this method is only applicable to materials with a minimal fiber volume fraction that can be assumed to be isotropic. Choi et al. (2019) used digital image correlation technology to analyze unidirectional carbon fiber reinforced composites through three shear test methods, i.e., in-plane $\pm 45^{\circ}$, Iosipescu shear test, and V-notch track shear test, and accurately measured the in-plane shear modulus of unidirectional carbon fiber. In order to explore whether carbon fiber and wood can be better integrated and further improve material properties, Novosel et al. (2021) studied the effect of implants 
made of carbon fiber reinforced polymer (CFRP) on improving the bending stiffness of laminated oak model beams in two directions. The four-point bending method was used to evaluate the stiffness, bending strength and overall ductility of the elastic area. It was shown that the reinforcement effect was best when one or two layers of carbon fiber with a width of $40 \mathrm{~mm}$ and $60 \mathrm{~mm}$ were implanted, and the effective stiffness could be increased by up to $94 \%$.

Most carbon fiber materials have the same anisotropy as wood, but the strength is not the same. In order to balance the production cost and mechanical properties of carbon fibers, isotropic pitch-based carbon fibers (IPCFs) are considered to be one of the most ideal candidate materials. However, there still have been relatively few studies on the elastic constant testing of IPCFs. With respects to these studies, dynamic testing and computational modal analysis of the elastic modulus, shear modulus, and Poisson's ratio of isotropic pitch-based carbon fiber (IPCFs) were carried out via the modal analysis method. Through the analysis of the coupling between the test model and computational model, the correctness and reliability of the elastic constant test of carbon fiber were ensured. In addition, the non-destructive testing level of the carbon fiber board material and the optimization design level of the dynamic characteristics were improved. This approach has practical significance to promote the development of the wood structure construction industry and further study the value of wood-carbon fiber composites.

\section{EXPERIMENTAL}

\section{Modal Test Analysis of Carbon Fiber Board Materials}

A piece of carbon fiber board was selected for this test. The model was T700, with the following specifications: dimensions of $430.5 \mathrm{~mm}$ (length) $\times 301.5 \mathrm{~mm}$ (width) $\times 1.88$ $\mathrm{mm}$ (thick), with a density of $1604.4 \mathrm{~kg} / \mathrm{m}^{3}$, and manufactured by Jiangsu Boshi Fiber Technology Co., Ltd. (Jiangsu, China). The manufacturing process primarily includes two stages, i.e., precursor production and precursor carbonization. Cut into fixed-length carbon fibers by SMC (Sheet Molding Compound) equipment, and make SMC preforms with the pre-prepared resin paste, and then put them in a constant temperature room for thickening and curing for 24 hours. The obtained SMC is vacuum molded with a vacuum hot press at $130{ }^{\circ} \mathrm{C}$ and a pressure of $2 \mathrm{MPa}$. After the SMC is cured, CFRP can be obtained. The main components of the resin matrix include unsaturated epoxy resin, vinyl resin, methyl ethyl ketone peroxide, cobalt isooctanoate accelerator, internal mold release agent and other auxiliary agents.

\section{Instruments and accessories}

A CRAS vibration signal acquisition and analysis system, which included an AZ308 data acquisition box, AZ-802 signal conditioning box and MaCars software, was manufactured by Nanjing Anzheng Software Engineering Co., Ltd (Nanjing, China). The JF-LC-1003 force hammer, with a sensitivity of $2.07 \mathrm{mV} / \mathrm{kN}$, a measurement range of 0 $\mathrm{kN}$ to $30 \mathrm{kN}$, a hammer head mass of $350 \mathrm{~g}$, a hammer handle length of $280 \mathrm{~mm}$, and a rubber buffer head mass of $69.1 \mathrm{~g}$, was manufactured by Yangzhou Jufeng Technology Co., Ltd. (Yangzhou, China). In addition, a TES-1350A sound level meter was used. 


\section{Test method and principle}

Based on the dynamic theory, the grid was divided on the free plate specimen of the carbon fiber board, with 6 equal parts in the length direction and 4 equal parts in the width direction. The single point vibration pickup and single point step excitation (SISO) methods of fixed measurement and moving excitation were adopted, and the force hammer excitation method, i.e., the sound level measurement point, was fixed (point 7), so that the specimen produces transverse free vibration. The sound level meter was used to receive the sound signal, and the sound signal was transformed into an electrical signal through the vibration signal acquisition and analysis system. After signal amplification, low-pass filtering, spectrum identification, and an orthogonal test, the modal parameters and mode shapes of the carbon fiber specimens were finally obtained, and the first-order bending frequency of the free plate specimens were also obtained (Wang et al. 2012, 2014, 2016a).

When the test plate vibrates laterally, the relationship between the elastic modulus (E) and the first-order bending frequency (fb) is shown in Eq. 1,

$$
\mathrm{E}=0.9462 \times \frac{\rho f_{b}^{2} l^{4}}{h^{2}}
$$

where $\rho$ is the density of the specimen $\left(\mathrm{kg} / \mathrm{m}^{3}\right), f_{\mathrm{b}}$ is the first-order bending frequency $(\mathrm{Hz})$, $l$ is the length of the specimen (m), and $h$ is the thickness of the specimen (m) (Gao et al. 2013).

When the test plate vibrates laterally, the relationship between the shear modulus (G) and the first-order torsional frequency ( $\mathrm{ft}$ ) is,

$$
\mathrm{G}=\frac{\pi^{2} \rho(l / 2)^{2} b^{2} f_{t}^{2}}{7.5 \beta h^{2}}
$$

where $\rho$ is the density of the specimen $\left(\mathrm{kg} / \mathrm{m}^{3}\right), f_{\mathrm{t}}$ is the first-order torsional frequency $(\mathrm{Hz})$, $l$ is the length of the specimen (m), $h$ is the thickness of the specimen (m), and $b$ is the width of the specimen (m) (Gao et al. 2016).

The system block diagram of the carbon fiber board free plate specimen is shown in Fig. 1.

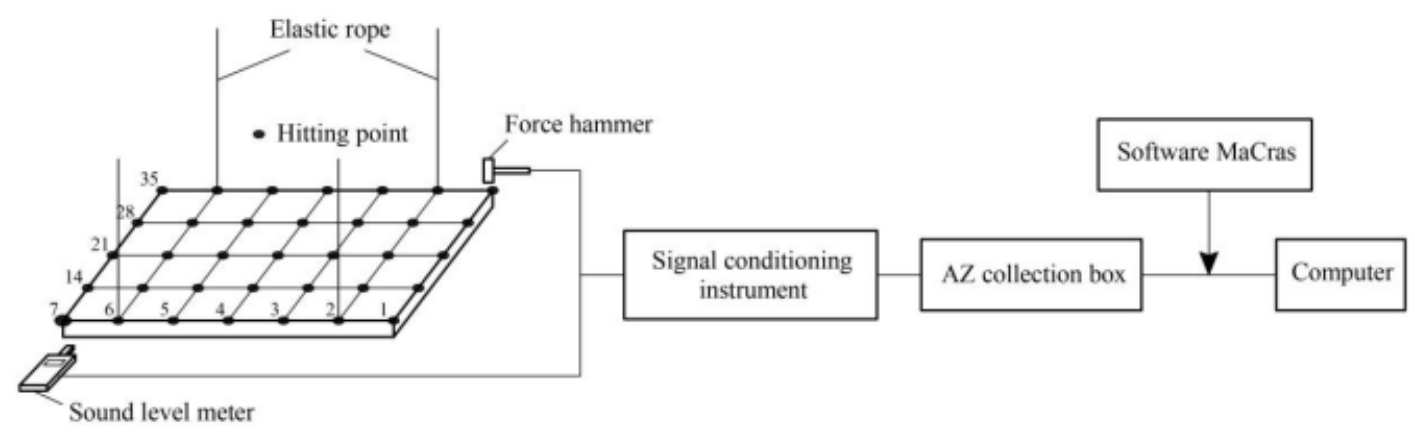

Fig. 1. Test block diagram of the free plate modal test

Test steps

A multi degree of freedom linear dynamic test system for the carbon fiber free plate specimens was realized, as shown in Fig. 2. 


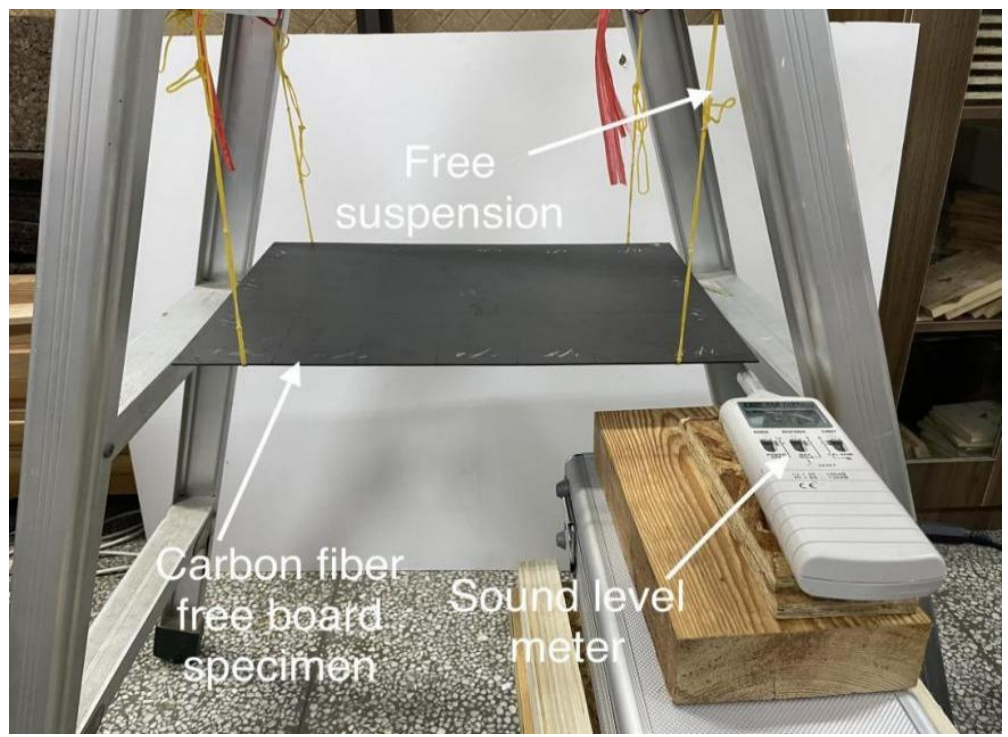

Fig. 2. Free plate modal test device

The data model was established using MaCars software. The parameter setting adopted the negative trigger mode, with a trigger level of $5 \%$, a voltage range of $\pm 625 \mathrm{mV}$, an analysis frequency of $200 \mathrm{~Hz}$, and a FFT block length of 1024.

According to the actual size of the carbon fiber board specimen, the model was established in MaCars, and its length and width directions were divided into 6 equal parts and 4 equal parts, respectively.

The sound level meter was placed, and the excitation points were divided. The measurement channel was set to 2 , and the number in the $\mathrm{Z}$ direction was 1 . During the test, the sound level meter was placed at point 7, via means of fixed measurement, single point vibration pickup of moving excitation, and single point step-by-step excitation (SISO). Through the force hammer excitation, the sound level measurement point (point 7) was fixed, the measurement method of the excitation point was changed, and the frequency response function of the fixed measurement point to each excitation point was measured. The SISO frequency response function identification method was used to complete the modal parameter identification by fitting the frequency response function curve.

\section{Dynamic Test of Poisson's Ratio}

Materials and instruments

The dimensions of the carbon fiber board specimen were $490 \mathrm{~mm}$ (length) $\times 25.21$ $\mathrm{mm}$ (width) $\times 3.51 \mathrm{~mm}$ (thickness), which was cut from the dimensions of $490.5 \mathrm{~mm}$ (length) $\times 301.5 \mathrm{~mm}$ (width) $\times 1.88 \mathrm{~mm}$ (thickness) board specimen, with a density of $1604.4\left(\mathrm{~kg} / \mathrm{m}^{3}\right)$. The test instrument and its supporting parts are a set of CRAS vibration signal acquisition and analysis systems, which included an AZ-308 data acquisition box, AZ-802 signal conditioning box, and MaCars software (Nanjing Anzheng Software Engineering Co., Ltd (Nanjing, China). In addition, a rubber hammer, cantilever clamping device, and a CA-YD-125 acceleration sensor (with a sensitivity of $15.9 \mathrm{PC} / \mathrm{m} \cdot \mathrm{s}^{2}$ and measurement range of $0 \mathrm{hz}$ to $20000 \mathrm{hz}$ ) were used. The sensitivity coefficient of the BX120-5AA strain gauge was $2.08 \% \pm 1 \%$, and the length and width of the strain grid were $5 \mathrm{~mm}$ and $3 \mathrm{~mm}$, respectively. 


\section{Test method and principle}

The carbon fiber board specimen was fixed with the cantilever plate holding device, which had a holding length of $275 \mathrm{~mm}$. The state of cantilever was completed, and an accelerometer was placed between the plate edge and the center line near the fixed end. Then, a $0^{\circ}$ to $90^{\circ}$ strain gauge was pasted on the cantilever plate, which was $0.4 \mathrm{~L}$ away from the clamping end. Next, the center line of the cantilever end of the specimen was hit with a rubber hammer to make the cantilever plate produce transverse vibration (Wang et al. 2015; Wang et al. 2016b). The test system block diagram is shown in Fig. 3.

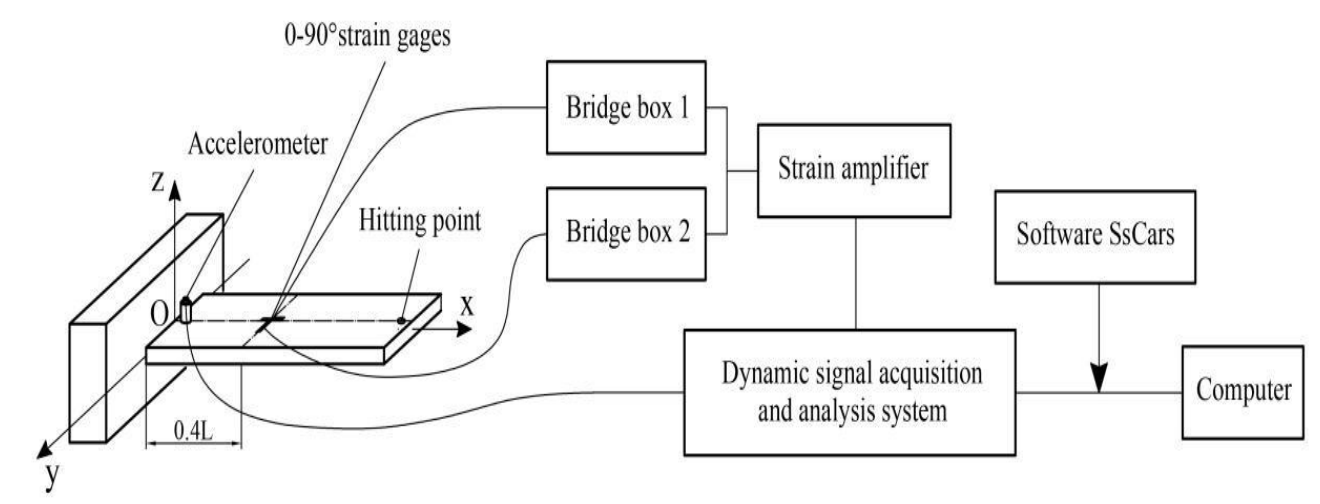

Fig. 3. Test block diagram of the cantilever plate

The relationship between Poisson's ratio and the strain in the transverse and longitudinal directions of the specimen is shown in Eq. 3,

$$
\mu_{i j}=-\varepsilon_{i} / \varepsilon_{j}
$$

where $\varepsilon_{\mathrm{i}}$ is the absolute value of transverse strain and $\varepsilon_{\mathrm{j}}$ is the absolute value of longitudinal strain. Poisson's ratio is always equal to the absolute value of the ratio of the transverse strain to the longitudinal strain (Wang et al. 2017).

\section{Test steps}

A strain gauge was pasted on the carbon fiber specimen on both sides, $0^{\circ}$ parallel in the length direction of the specimen and $90^{\circ}$ perpendicular in the length direction of the specimen. Then, the pasted specimen was fixed with the cantilever holding device and an accelerometer was placed near the center line of the fixed support end (Fig. 4). Then, the strain gauge was connected with the bridge box and the strain amplifier successively via a wire. The strain amplifier was connected with channel 1 and 2 of the dynamic signal acquisition and analysis system, in which one was connected with the $0^{\circ}$ piece and two were connected with the $90^{\circ}$ piece to realize a half bridge connection. Finally, the accelerometer was connected to the three channels of the dynamic signal acquisition and analysis system.

SsCars software was used for testing, with the following primary parameter settings: an analysis frequency of $1000 \mathrm{~Hz}$, a FFT block length of 1024, and using the negative trigger mode with a trigger level of $25 \%$.

Then, the cantilever plate was hit with the hammer, and its spectrum diagram was recorded (Fig. 5). The amplitude of the first-order bending frequency was replaced, corresponding to the $0^{\circ}$ to $90^{\circ}$ strain gauge, i.e., the strain value, into Eq. 3 to obtain its Poisson's ratio, which are shown in Table 1. 


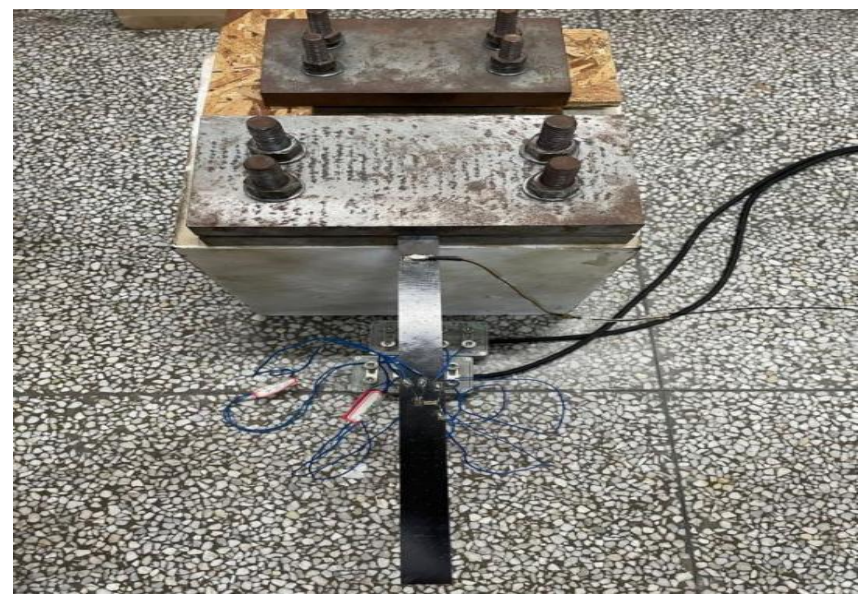

Fig. 4. Cantilever plate test device



Fig. 5. Test spectrum of the cantilever plate

Table 1. Parameters and Test Results of the Cantilever Plate Specimen

\begin{tabular}{|c|c|c|c|c|c|c|c|}
\hline $\begin{array}{c}\text { Order } \\
\text { Number }\end{array}$ & $\begin{array}{c}\text { Length } \\
(\mathrm{mm})\end{array}$ & $\begin{array}{c}\text { Width } \\
(\mathrm{mm})\end{array}$ & $\begin{array}{c}\text { Thickness } \\
(\mathrm{mm})\end{array}$ & $\begin{array}{c}\text { Density } \\
\left(\mathrm{kg} / \mathrm{m}^{3}\right)\end{array}$ & $\varepsilon_{0^{\circ}}$ & $\varepsilon_{90^{\circ}}$ & $\mu_{90-0^{\circ}}$ \\
\hline 1 & 275 & 25.21 & 3.51 & 1604.4 & 20.48 & 9.51 & 0.46 \\
\hline 2 & 275 & 25.21 & 3.51 & 1604.4 & 21.79 & 10.05 & 0.46 \\
\hline 3 & 275 & 25.21 & 3.51 & 1604.4 & 26.59 & 12.01 & 0.46 \\
\hline 4 & 275 & 25.21 & 3.51 & 1604.4 & 24.35 & 10.87 & 0.45 \\
\hline 5 & 275 & 25.21 & 3.51 & 1604.4 & 22.08 & 10.40 & 0.47 \\
\hline Mean & 275 & 25.21 & 3.51 & 1604.4 & 23.06 & 10.57 & 0.46 \\
\hline
\end{tabular}




\section{RESULTS AND DISCUSSION}

\section{Modal Test Results and Analysis}

The mode shape of the carbon fiber specimen measured in this modal test are shown in Figs. 6 through 8.

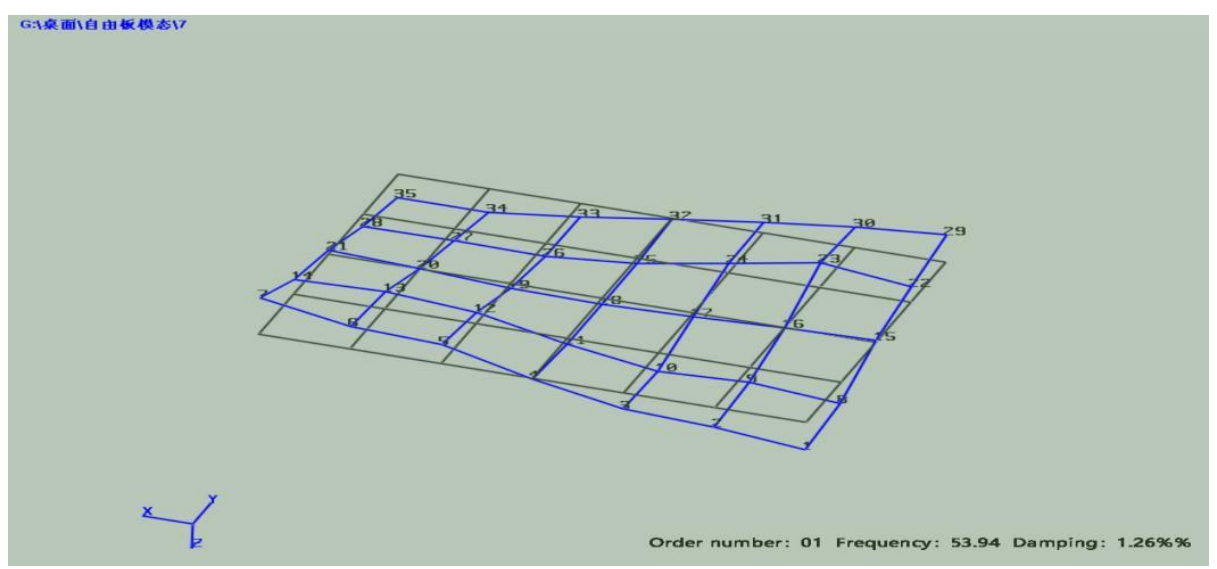

Fig. 6. The first-order torsional mode of the free-plate



Fig. 7. The first-order bending mode of the free-plate

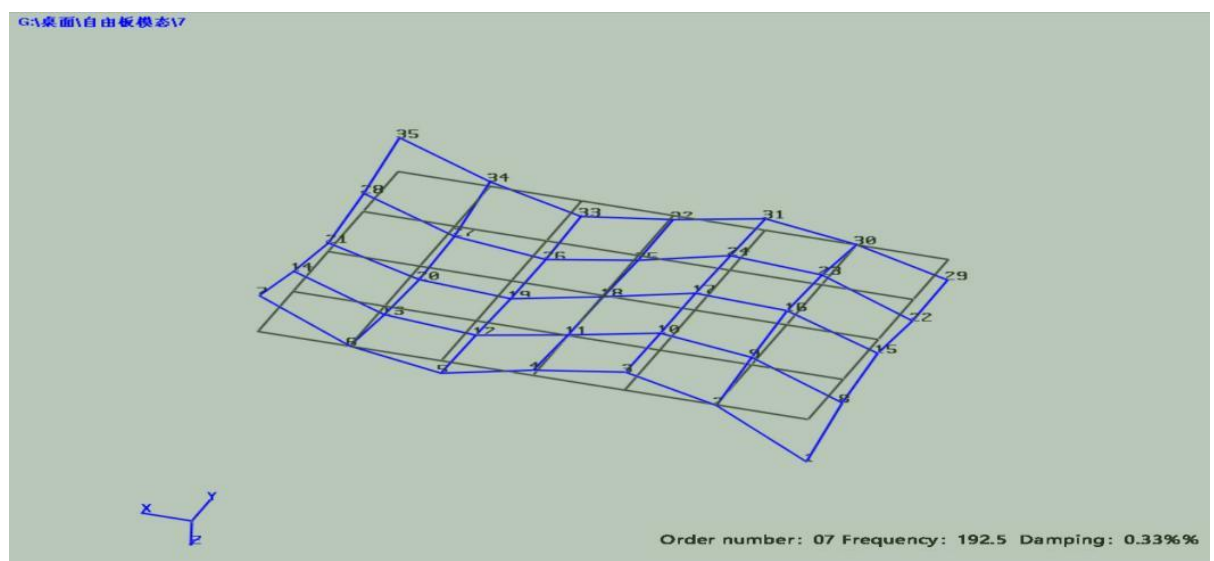

Fig. 8. The second-order bending mode of the free-plate 
According to its mode shape, the first-order torsion mode and the first-order bending mode and their corresponding frequencies and damping ratios are shown in Table 2 .

Table 2. Mode Natural Frequency and Damping Ratio

\begin{tabular}{|c|c|c|}
\hline Content & First-order Torsional Mode & First-order Bending Mode \\
\hline Mode frequency $(\mathrm{Hz})$ & 53.94 & 66.24 \\
\hline Damping ratio $(\%)$ & 1.26 & 0.15 \\
\hline
\end{tabular}

It can be seen from Table 2 that the first-order bending frequency and first-order torsional frequency obtained from the modal test of free plate specimen were $66.24 \mathrm{~Hz}$ and $53.94 \mathrm{~Hz}$, respectively. As such, the elastic modulus $(E)$ and shear modulus $(G)$ were 64700 $\mathrm{MPa}$ and 22,200 MPa, respectively, as calculated from Eqs. 1 and 2, respectively.

\section{Computational Modal Analysis}

In order to analyze the mode shapes and modal parameters of the carbon fiber board obtained by the above modal test method via the finite element theory and calculate the coupling of the elastic modulus and shear modulus, it is necessary to carry out a computational modal analysis of the carbon fiber board.

\section{Procedure}

Solidworks 2020 (Dassault Systèmes, Vélizy-Villacoublay, France) was used to model the specimens in this study, and the finite element modal analysis was performed in Workbench 19.1 (Ansys, Canonsburg, PA) for carbon fiber board material properties. The material properties are shown in Table 3.

Table 3. Material Properties of the Carbon Fiber in the Computational Model

\begin{tabular}{|c|c|c|c|c|c|c|}
\hline Parameter & $\begin{array}{c}\text { Density } \\
\left(\mathrm{kg} / \mathrm{m}^{3}\right)\end{array}$ & $\begin{array}{c}\text { Length } \\
(\mathrm{mm})\end{array}$ & $\begin{array}{c}\text { Width } \\
(\mathrm{mm})\end{array}$ & $\begin{array}{c}\text { Thickness } \\
(\mathrm{mm})\end{array}$ & $\begin{array}{c}\text { The Elastic Modulus } \\
(E)(\mathrm{MPa})\end{array}$ & $\begin{array}{c}\text { Poisson's } \\
\text { Ratio }\left(\mu_{\mathrm{ij}}\right)\end{array}$ \\
\hline Specimen & 1604.4 & 430.5 & 301.5 & 1.88 & 64731 & 0.46 \\
\hline
\end{tabular}

The carbon fiber specimen was meshed, the node of the specimen was 1576, and the sensitivity of the mesh size was analyzed. The maximum mode calculation was set to order 20 , free and unconstrained boundary conditions were set before calculation.

Computational modal results and analysis

The first-order torsional mode, first-order bending mode, and second-order bending mode of the specimen calculated via the finite element method are shown in Figs. 9 through 11 , respectively. The calculated values are shown in Table 4 


\section{bioresources.com}

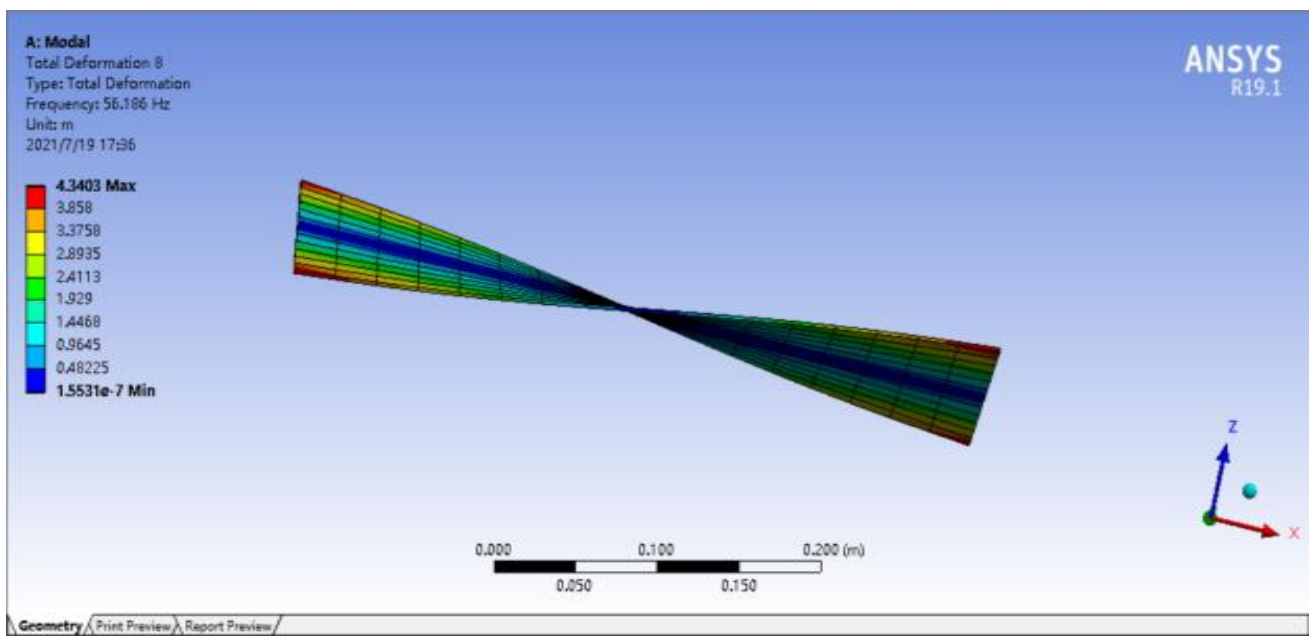

Fig. 9. The first-order torsional mode of the computational modal analysis

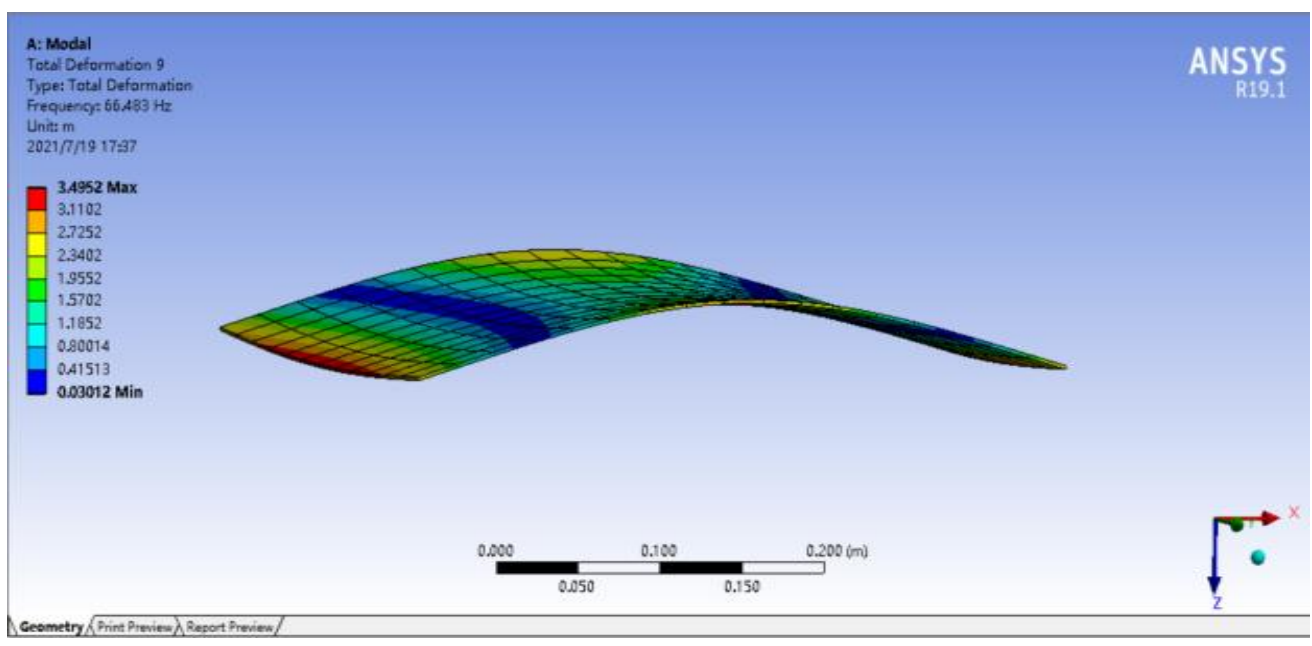

Fig. 10. The first-order bending mode of the computational modal analysis

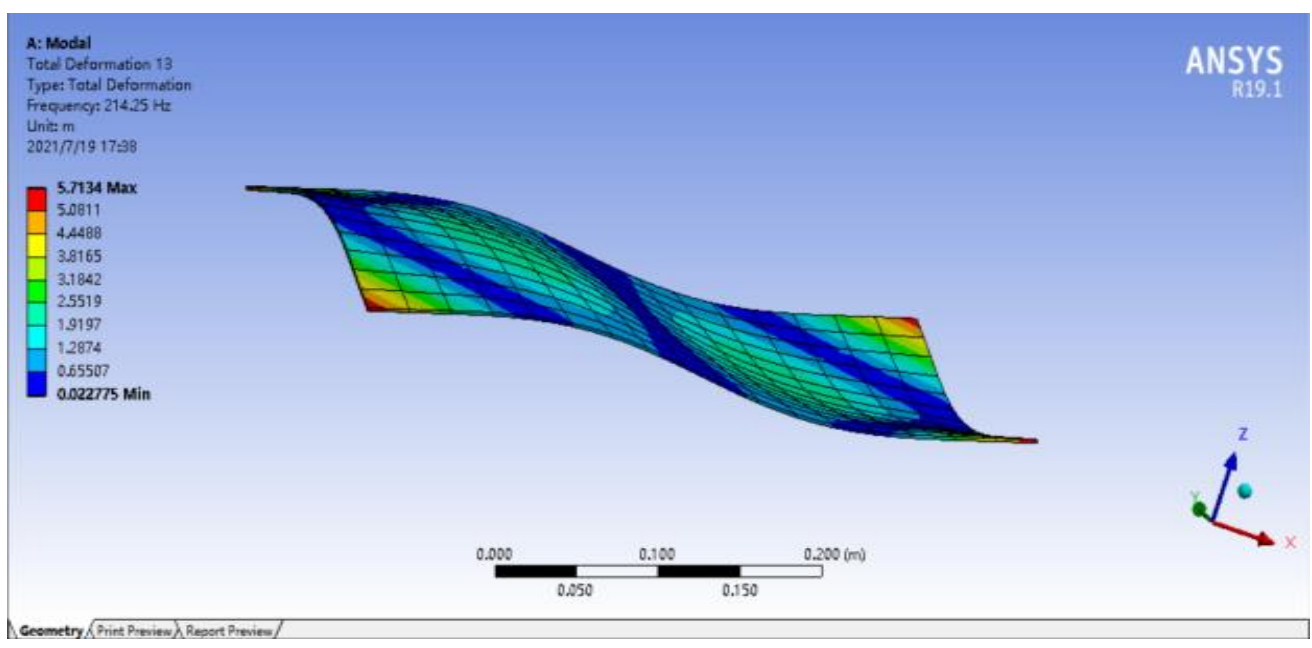

Fig. 11. The second-order bending mode of the computational modal analysis 
Table 4. Computational Modal Natural Frequency

\begin{tabular}{|c|c|c|}
\hline Content & First-order Torsional Mode & First-order Bending Mode \\
\hline Mode frequency $(\mathrm{Hz})$ & 56.19 & 66.48 \\
\hline
\end{tabular}

\section{Test Modal and Computational Modal Results and Analysis}

It is known from the calculation results that the test model was consistent with the computational model, and the corresponding mode frequency values are shown in Table 5.

Table 5. Computational Model and Test Model Results

\begin{tabular}{|c|c|c|c|}
\hline Parameter & Test Model & $\begin{array}{c}\text { Computational } \\
\text { Model }\end{array}$ & Error Frequency \\
\hline Length $(\mathrm{mm})$ & 430.5 & 430.5 & - \\
\hline Width $(\mathrm{mm})$ & 301.5 & 301.5 & - \\
\hline Thick $(\mathrm{mm})$ & 1.88 & 1.88 & - \\
\hline Density $\left(\mathrm{kg} / \mathrm{m}^{3}\right)$ & 1604.4 & 1604.4 & $4 \%$ \\
\hline First-order torsional mode $(\mathrm{Hz})$ & 53.94 & 56.19 & $0 \%$ \\
\hline First-order bending mode $(\mathrm{Hz})$ & 66.24 & 66.48 & $0.7 \%$ \\
\hline The elastic modulus $(\mathrm{E})(\mathrm{MPa})$ & 64731 & 65207 & - \\
\hline The shear modulus $(\mathrm{G})(\mathrm{MPa})$ & 22160 & 24044 & - \\
\hline Poisson's ratio $(\mu)$ & 0.46 & 0.46 & \\
\hline
\end{tabular}

As the natural frequency is the primary parameter of vibration characteristics and the natural characteristics of the object, it is only related to the stiffness, mass, and overall dimensions of the object. Therefore, the natural frequency can be used as the strength index of the object under certain conditions for the detection of mechanical properties (Guo 2013).

According to Table 5, the error frequencies of the $\mathrm{E}$ and $\mathrm{G}$ values calculated by the computational modal and test modal were $0.7 \%$ and $7.8 \%$, respectively, which indicated that the two analysis results had a high degree of coupling (Wang and Ghanem 2021; Zhou et al. 2021).

\section{CONCLUSIONS}

1. Based on the test modal analysis and computational modal analysis of carbon fiber boards, the elastic modulus, shear modulus, and Poisson's ratio of a carbon fiber board can be obtained accurately and reliably.

2. The computational modal analysis was consistent with the first-order bending and firstorder torsional of the test modal analysis; the frequency error was within 5\%, and the error rates of $\mathrm{E}$ and $\mathrm{G}$ were $0.7 \%$ and $7.8 \%$, respectively. This showed that the coupling degree of the two analysis results were high, and the correctness and reliability of the mode shape and elastic constant of carbon fiber boards can be well realized.

3. At the same time, the research was conducive to strengthening the use of finite element computational modal analysis and better promote its application in the nondestructive 
testing and quality grading of carbon fiber boards, which has engineering application value for improving the optimal design of the dynamic characteristics of carbon fiber board and promoting the faster development of the wood structure market. At the same time, it provides convenience for the dynamic testing and research of the elastic constants of wood-carbon fiber composites in the future.

\section{REFERENCES CITED}

Ashraf, M., Hasan, M. J., and Al-Deen, S. (2021). "Semi-rigid behaviour of stainless steel beam-to-column bolted connections," Sustainable Structures 1(1), 1-14. DOI: $10.54113 /$ j.sust.2021.000002

ASTM C1556 (2014). "Standard test method for tensile strength and Young's modulus of fibers," ASTM International, West Conshohocken, PA.

Chen, R., and Wang, X. (2010). "The performance, application and related standards of polyacrylonitrile-based (PAN) carbon fiber," China Fiber Inspection 2010(11), 7579.

Choi, J.-H., Jang, J., Shim, W., Cho, J.M., Yoon, S.-.J., Choi, C.-H., Han, H. N., and Yu, W.-R. (2019). "Determination of the in-plane shear modulus of unidirectional carbon fiber-reinforced plastics using digital image correlation and finite-element analysis," Composite Structures 229, article no. 111392. DOI: 10.1016/j.compstruct.2019.

Corbi, O., Baratta, A., Corbi, I., Tropeano, F., and Liccardo, E. (2021). "Design issues for smart seismic isolation of structures: Past and recent research," Sustainable Structures 1(1), 1-11. DOI: 10.54113/j.sust.2021.000001

Dauletbek, A., Li, H., Xiong, Z., and Lorenzo, R. (2021). "A review of mechanical behavior of structural laminated bamboo lumber," Sustainable Structures 1(1), 1-19. DOI: $10.54113 /$ j.sust.2021.000004

Duan, S., Liu, F., Pettersson, T., Creighton, C., and Asp, L. E. (2020). "Determination of transverse and shear moduli of single carbon fibres," Carbon 158, 772-782. DOI: 10.1016/j.carbon.2019.11.054

Gao, Z., Cao, Y., Xue, C., Shi, M., and Wang, Z. (2013). "Study on the measured elastic modulus of sawn timber by two dynamic methods," Forestry Machinery \& Woodworking Equipment 41(04), 23-26. DOI:10.19531/j.issn1001-5299.2013-04-003

Gao, Z., Wang, Z., Zhang, X., Xu, L., and Liu, B. (2016). "Frequency method test and analysis of the soundboard shear modulus of Western Canada spruce wood," Forest Products Industry 43(2), 23-26. DOI: 10.19531/j.issn1001-5299.2016.02.010

Gezer, H., and Aydemir, B. (2010). "The effect of the wrapped carbon fiber reinforced polymer material on fir and pine woods," Materials and Design 31(7), 3564-3567. DOI: $10.1016 /$ j.matdes.2010.02.031

Guo, J. (2013). Numerical Simulation and Testing of Vibration Modes of Wood Plywood, Master's Thesis, Chinese Academy of Forestry, Beijing, China.

Guruprasad, T. S., Keryvin, V., Charleux, L., Guin, J.-P., and Arnould, O. (2020). “On the determination of the elastic constants of carbon fibres by nanoindentation tests," Carbon 173, 572-586. DOI: 10.1016/J.CARBON.2020.09.052

Kim, M., Park, Y.-B., Okoli, O. I., and Zhang, C. (2009). "Processing, characterization, and modeling of carbon nanotube-reinforced multiscale composites," Composites Science and Technology 69(3-4), 335-342. DOI: 10.1016/j.compscitech.2008.10.019 
Li, Y.-F., Xie, Y.-M., and Tsai, M.-J. (2007). "Enhancement of the flexural performance of retrofitted wood beams using CFRP composite sheets," Construction and Building Materials 23(1), 411-422. DOI: 10.1016/j.conbuildmat.2007.11.005

Liang, R., Stanislawski, D., and Hota, G. (2021). "Material characterization and structural response under earthquake loads of hakka rammed earth building," Sustainable Structures 1(1), 1-17. DOI: 10.54113/j.sust.2021.000003

Mesquita, F., Bucknell, S., Leray, Y., Lomov, S. V., and Swolfs, Y. (2021). "Single carbon and glass fibre properties characterised using large data sets obtained through automated single fibre tensile testing," Composites Part A: Applied Science and Manufacturing 145, 106389. DOI: 10.1016/J.COMPOSITESA.2021.106389

Novosel, A., Sedlar, T., Cizmar, D., Turkulin, H., and Zivkovic, V. (2021). "Structural reinforcement of bi-directional oak-wood lamination by carbon fibre implants," Construction and Building Materials 287, article no. 123073. DOI: 10.1016/j.conbuildmat.2021.

Wang, L. (2012). High-frequency Physical Properties and Application Research of Fiber Composite Materials, Master's Thesis, Nanjing University, Nanjing, China.

Wang, Z., Li, L., and Gong, M. (2012). "Dynamic modulus of elasticity and damping ratio of wood-based composites using a cantilever beam vibration technique," Construction and Building Materials 28(1), 831-834. DOI:

10.1016/j.conbuildmat.2011.09.001

Wang, Z., Wang, Z., Wang, B. J., Wang, Y., Liu, B., Rao, X., Wei, P., and Yang, Y. (2014). "Dynamic testing and evaluation of modulus of elasticity (MOE) of SPF dimension lumber," BioResources 9(3), 3869-3882. DOI: 10.15376/biores.9.3.38693882

Wang, Z., Gao, Z., Wang, Y., Cao, Y., Wang, G., Liu, B., and Wang, Z. (2015). "A new dynamic testing method for elastic, shear modulus and Poisson's ratio of concrete," Construction and Building Materials 100, 129-135. DOI:

10.1016/j.conbuildmat.2015.09.060

Wang, Z., Wang, G., Wang, Y., Cao, Y., and Gao, Z. (2016a). "Determination of wood shear modulus by torsion mode method of free plate," Journal of Forestry Engineering 2016(4), 10-17. DOI: 10.13360/j.issn.2096-1359.2016.04.002

Wang, Z., Wang, Y., Cao, Y., and Wang, Z. (2016b). "Measurement of shear modulus of materials based on the torsional mode of cantilever plate," Construction and Building Materials 124, 1059-1071. DOI: 10.1016/j.conbuildmat.2016.08.104

Wang, Z., Cao, Y., Wang, Y., and Li, M. (2017). "Test material shear modulus based on cantilever plate torsion mode," Forestry Science 53(8), 101-112. DOI: CNKI:SUN:LYKE.0.2017-08-012

Wang, Z., and Ghanem, R. (2021). "An extended polynomial chaos expansion for PDF characterization and variation with aleatory and epistemic uncertainties," Computer Methods in Applied Mechanics and Engineering 382, 113854. DOI: 10.1016/J.CMA.2021.113854

Xuan, Y., Li, H., Bei, Z., Xiong, Z., Lorenzo, R., Corbi, I., and Corbi, O. (2021). "Nodes effect on the bending performance of Laminated Bamboo Lumber Unit," Journal of Renewable Materials 9(6), 1143-1156. DOI: 10.32604/jrm.2021.015292

Yang, R., Li, H., Dauletbek, A., Ashraf, M., Lorenzo, R., Sun, Y., and Wu, Y. (2021). "Effect of freeze-thaw cycles on physical and mechanical properties of glulam exposed to outdoor environment," Journal of Renewable Materials 9(7), 1293-1307. DOI: $10.32604 / j \mathrm{rm} .2021 .015296$ 
Yang, Z. (2011). "Low-carbon economy brings opportunities for the development of new lightweight carbon fiber materials," Chemical Industry 29(Z1), 1-5. DOI: CNKI:SUN:HGJJ.0.2011-Z1-000

Zhang, H., Li, H., Hong, C., Xiong, Z., Lorenzo, R., Corbi, I., and Corbi, O. (2021). "Size effect on the compressive strength of laminated bamboo lumber," Journal of Materials in Civil Engineering 33(7), 1-12. DOI: 10.1061/(ASCE)MT.19435533.0003776

Zhou, Y., Huang, Y., Sayed, U., and Wang, Z. (2021). "Research on dynamic characteristics test of wooden floor structure for gymnasium," Sustainable Structures 1(1), 1-10. DOI: 10.54113/j.sust.2021.000005

Article submitted: September 27, 2021; Peer review completed: November 6, 2021;

Revised version received: November 9, 2021; Accepted: November 10, 2021; Published: November 17, 2021.

DOI: $10.15376 /$ biores.17.1.255-268 